\title{
PROCESSOS DE COMUNICAÇÃO DAS OPE- RADORAS DE SAÚDE: APONTAMENTOS PARA UTILIZAÇÃO DA INTERNET PARA PROMOÇÃO DA SAÚDE NO BRASIL
}

\author{
PAOLA LANZALOTTA MARCELINO \\ UNIVERSIDADE FERNANDO PESSOA \\ CIDADE DO PORTO, PORTUGAL \\ PAOLA@IS1.COM.BR \\ JORGE PEDRO SOUSA \\ UNIVERSIDADE FERNANDO PESSOA \\ CIDADE DO PORTO, PORTUGAL \\ JPSOUSA@UFP.EDU.PT \\ MOZAHIR SALOMÃO BRUCK \\ PONTIFÍCIA UNIVERSIDADE CATÓLICA DE MINAS GERAIS \\ BELO HORIZONTE, MINAS GERAIS, BRASIL \\ MOZAHIR@UOL.COM.BR
}

HTTP://DX.DOI.ORG/10.5902/2316882X28866 
PROCESSOS DE COMUNICAÇÃO DAS OPERADORAS DE SAÚDE: APONTAMENTOS PARA UTILIZAÇÃO DA INTERNET PARA PROMOÇÃO DA SAÚDE NO BRASIL

Resumo: O presente artigo busca debater sobre processos de comunicação e sobre rearranjos teóricos recentes quanto à comunicação organizacional, direcionados a utilização da internet para promoção da saúde no Brasil. Discute também como o papel das mídias sociais pode ser determinante em ações que tem como primazia novas estratégias nesse sentido, sobretudo para empresas operadoras de saúde.

Palavras chave: Comunicação organizacional; Operadoras de saúde; Internet

PROCESOS DE COMUNICACIÓN DE LAS OPERADORAS DE SALUD: APUNTES PARA UTILIZACIÓN DE INTERNET PARA PROMOCIÓN DE LA SALUD EN BRASIL

Resumen: El presente artículo busca debatir sobre procesos de comunicación y sobre reajustes teóricos recientes en cuanto a la comunicación organizacional, dirigidos a la utilización de Internet para promoción de la salud en Brasil. También discute cómo el papel de los medios sociales puede ser determinante en acciones que tienen como primacía nuevas estrategias en ese sentido y para empresas operadoras de salud.

Palabras clave: Comunicación organizacional; Operadoras de salud; Internet

COMMUNICATION PROCESSES OF HEALTH CARE PROVIDERS: NOTES FOR USE OF THE INTERNET FOR HEALTH PROMOTION IN BRAZIL

Abstract: This article aims to discuss communication processes and recent theoretical rearrangements regarding organizational communication, directed to the use of the internet for health promotion in Brazil. It also discusses how the role of social media can be decisive in actions that have as a priority new strategies in this sense, especially for healthcare companies.

Keywords: Organizational communication; Health care workers; Internet

Rev.Cad.Comun. Santa Maria, v.22, n.1, art 7, p.144 de 169, jan/abr.2018 


\section{INTRODUÇÃO}

Marco na evolução tecnológica e comunicacional, em meados da primeira década dos anos 2000, o advento da Web 2.0 trouxe nova concepção, mais dinâmica de uso da internet. Ela intensificou o modo de interagir e colaborar através de uma comunicação multidirecional (GOLD et al., 2012; PARK; RODGERS; STEMMLE, 2011; RAMANADHAN et al., 2013). No desdobramento dessa nova abordagem do ambiente cibernético, houve o surgimento dos Sites de Redes Sociais (SRS). Em sua essência, são ferramentas que permitem aos indivíduos manter vínculos de relacionamentos, além de possibilitar troca de mensagens públicas e privadas, postagens de fotos e de vídeos e compartilhamento de outros conteúdos. O Facebook, Twitter, Linkedin e MySpace são os exemplos mais populares mundialmente (Gold et al., 2012).

De seu surgimento até hoje, o crescimento dessas redes interativas tem determinado, assim, todo o campo discursivo e institucional, quando se pensa a comunicação organizacional, sendo também determinante em muitos fatores para condutas humanas, como, por exemplo, na disseminação de informações sobre doenças, tratamentos, etc. ou em novas definições para a realização de intervenções de em saúde. Entretanto, a ideia de saúde vai além dessa relação doença e tratamento.

O conceito é definido pela Organização Mundial de Saúde [OMS] (2003), como sendo "um estado dinâmico de completo bem-estar físico, mental, espiritual e social e não apenas a ausência de doença ou enfermidade". Com base nessa noção ampla, um marco conceitual e estratégico, no sentido da melhoria da saúde da população, foi estabelecido a partir da ideia de promoção da saúde. Esta é entendida por O’Donnell (2008, p. 2) como a ciência e arte de ajudar as pessoas a mudar seu estilo de vida para se moverem em direção a um estado de saúde ideal, que se constitui num processo de engajamento por um equilíbrio dinâmico entre as dimensões física, emocional, social, espiritual e intelectual e a descoberta da sinergia entre os seus aspectos mais positivos.

Para muitos teóricos, a internet hoje imputa sua dinamicidade rumo ao entendimento da comunicação pelo viés relacional, que implica concebê-la como um processo dinâmico de construção conjunta entre interlocutores (sujeitos sociais), a partir de discursos (formas simbólicas que trazem as marcas de sua produção, dos sujeitos envolvidos e do contexto), em situações singulares (dentro de um determinado contexto) (FRANÇA et al., 2002;

Rev.Cad.Comun. Santa Maria, v.22, n.1, art 7, p.145 de 169, jan/abr.2018 
FRANÇA, 2001; LIMA; ABBUD, 2015). Para Lima (2008, p. 10), baseando-se em Mead (1962), a configuração dialógica, como as suscitadas na internet, tornam as interações ações reciprocamente referenciadas que, juntas, fundam, num mesmo movimento, indivíduo e sociedade.

No bojo desse panorama, os sites de redes sociais podem ser determinantes em ações que tem como primazia novas estratégias de promoção de saúde. Isso suscita grandes oportunidades adicionais a serem exploradas pelas empresas, ao alavancar o relacionamento e a interação com os sujeitos procurando, cada vez mais, se ajustar ao potencial do Facebook, em prol da promoção da saúde do indivíduo e da sociedade.

Ao mesmo tempo, estudos vêm reiterando o fato de que a comunicação organizacional de muitas instituições parece não ter acompanhado a evolução de suas práticas estando, a despeito do aparecimento dos sites de redes sociais, em descompasso com elas. Para esses autores, essa comunicação é, ainda, marcada por um viés predominantemente tecnicista, gerencial e prescritivo. Por isso reforçam a necessidade de adoção de uma nova perspectiva que permita a conexão e a relação entre os interlocutores (BALDISSERA, 2010; LIMA, 2008; OLIVEIRA; PAULA, 2005).

Apesar de primordial, a comunicação organizacional, nesse tipo de perspectiva anterior, na maioria das vezes se dá pela cristalização de condutas e conceitos que, como se sabe, é parte do que orienta os preceitos por trás de uma organização. Quanto a isso, estudos têm notado a importância de avanços nos padrões e visões organizacionais que se adequem a atual conjuntura, trazida pelo instante tecnológico comunicacional, bem com a suplantação do paradigma clássico, que envolvia figuras estáticas de organização, e era calcada num tipo de comunicação organizacional de um emissor ativo e um público como receptor inerte (ALBUQUERQUE; RODELLA, 2012; BALDISSERA, 2010; GOLD et al., 2011; GOLD et al., 2012).

Sabe-se que tem toda relação comercial existe a necessidade de troca comunicacional. Isso não é menos verdade para as operadoras de saúde e sua rede de associados e usuários. E no que se refere à comunicação, essa relação é em parte regulada graças a arranjos teóricos resultantes de pesquisas e estudos que estabeleceram modelos e modos de que tal aconteça, como no campo de estudo da comunicação organizacional.

Deste modo, o presente artigo busca debater sobre processos de comunicação e sobre rearranjos teóricos recentes quanto à comunicação organizacional, direcionados a utilização da internet para promoção da saúde no 
Brasil.

\section{QUESTÕES INICIAIS SOBRE O PARADIGMA DIALÓGICO DA COMU- NICAÇÃO}

Os estudos evocados como pioneiros na inauguração da área em comunicação, do início de século XX, foram voltados para a caracterização e análise das novas práticas comunicativas, centrados nos meios de comunicação que despontavam no final do século XIX e marcam o século XX: o surgimento da imprensa de massa, do rádio, da televisão (e do cinema, em menor grau) (FRANÇA, 2001). Para França (2001), tais estudos, que determinarão o olhar das pesquisas durante muito tempo, tem um problema na eleição do seu objeto, já que ele esta baseado no pressuposto de uma ilusória autonomia e precisão dos contornos da empiria. Desse modo, se equivocariam, já que

os objetos do mundo não estão dados de antemão, nem são recortados por suas leis intrínsecas - mas constituídos e dispostos pelo olhar e intervenção dos homens. Assim, os meios de comunicação ou a mídia, na sua aparente objetividade e simplicidade, não o são tanto assim, mas se desdobram em múltiplas dimensões - tais como a técnica, a política, a economia, o consumo, a vida urbana, as práticas culturais, a sociabilidade etc. Dimensões estas que não apenas irão "compor" o nosso objeto, mas se desenvolvem por caminhos próprios.

Para tentar explicar o fenômeno da comunicação, os primeiros estudos da área se assentavam no que hoje convencionamos chamar de paradigma informacional. Esse paradigma busca entender a

a comunicação como um processo de transmissão de mensagens de um emissor para um receptor, provocando determinados efeitos, supostamente por um movimento analítico de duas direções, pautado na naturalidade e evidência da lógica transmissiva, as análises vão se ocupar dos seus resultados: uma dada mensagem foi ou não bem transmitida, provocou que tipo de efeitos. Um segundo caminho, dado que o processo é tomado mecanicamente, e cada um de seus elementos tem seu papel fixo, definido previamente, é estudá-los separadamente: estuda-se a lógica da produção, dos emissores; a característica dos meios (natureza técnica, modos operatórios); as mensagens (conteúdos); a posição e atitude dos receptores (FRANÇA, 2001). 
Avançada a discussão ao longo dos anos, após esses trabalhos primordiais, diversos teóricos irão tentar referenciar novos paradigmas que dessem conta dos diversos matizes do ato comunicacional, para além daqueles equívocos, como mostrado pelo paradigma dialógico. Ele distingue a comunicação (em contraposição à relação informativa) a partir da bilateralidade do processo, da igualdade de condições e funções estabelecidas entre os interlocutores, com ênfase na natureza da relação entre os dois polos (FRANÇA, 2001).

As teorias dialógicas encontram as suas raízes em autores como Mikhail Bakhtin que torna o diálogo como a substância da linguagem e do conhecimento, de forma que é o processo de interação que conduz ao conhecimento, reivindicando uma interpretação participativa, integradora, social, diversa e múltipla na comunicação e conhecimento (LENCASTRE; MONTEIRO, 2009). Por isso, se caracterizariam como tentativa de superação dos princípios do dualismo, do instrumentalismo e do perfeccionismo que têm pautado o pensamento ocidental (SOUZA, 2010).

Pensar a comunicação como processo interativo e dialógico

é reafirmar sua natureza relacional, de colocar em relação elementos que adquirem significação a partir de um compartilhamento de sentido, ou seja, a partir da relação entre interlocutores e suas (inter) subjetividades, mensagens e o contexto da relação, na produção de um significado, de uma compreensão da intencionalidade, que caracteriza, enfim, o ato comunicativo. É um processo que nitidamente exige uma constante elaboração, uma constante construção (OLIVEIRA; PAULA, 2005, p. 20).

Ou seja, a comunicação só tem sentido na relação. Sugestivamente, a construção do conhecimento em rede, a estruturação comunicacional da internet, a hipertextualidade, entre outros, são marcas atuais dessa lógica comunicacional (MELLO, 2010).

\section{SOCIEDADE DA INFORMAÇÃO: COMUNICAÇÃO EM REDE E INTE- RATIVIDADE}

Para muitos autores (CARDOSO, 2010; LUCENA FERREIRA; BIANCHETTI, 2004; NICOLAU, 2011), é na internet que a comunicação dialógica parece conformar-se. Na dinâmica de desenvolvimento das novas tecnologias da informação,

Rev.Cad.Comun. Santa Maria, v.22, n.1, art 7, p.148 de 169, jan/abr.2018 
a internet ampliou muito rapidamente o seu poder de integração e compatibilização de mídias, programas e sistemas comunicacionais. E seu caráter digital vem permitindo que se estabeleçam modelos efetivamente interativos de comunicação. Dentro desse contexto midiático estão se configurando formas de relacionamentos interpessoais e coletivos, bem como entre pessoas e organizações baseadas em laços fracos, mas com tendência a se tornarem bem mais forte a partir das condições interativas disponíveis à ambas as partes (NICOLAU, 2011, p. 2).

Essa nova realidade midiática e comportamental, segundo Nicolau (2011), tem assim exigido a construção de novos modelos de comunicação que permitam uma compreensão mais apropriada desse processo e uma visão sistêmica da comunicação. E os avanços nas tecnologias da informação e comunicação (TIC), por sua vez, são

altamente contributivos para criar condições de modificar as formas das pessoas se relacionarem, construírem e transmitirem conhecimentos. Por meio dessas tecnologias, é possível a construção do conhecimento coletivo com sujeitos localizados em espaços e tempos distintos, mas que integram o mesmo ambiente virtual ou a mesma comunidade virtual de aprendizagem. As formas de buscar informações e de divulgá-las a um maior número de pessoas também foram alteradas com a disponibilização dessas tecnologias (LUCENA FERREIRA; BIANCHETTI, 2004, p. 254).

Ou seja, a internet tem permitido que cada pessoa, além de acessar informações, disponibilize também as suas produções, partilhando, trocando, intervindo nas informações produzidas por outras pessoas (KRUSCHEWSKY; KRUSCHEWSKY; CARDOSO, 2016).

A ideia de interatividade está imbuída nesse ambiente, que extrapola sua acepção inicial e se vale de catalizador desse ambiente. Valle e Bohadana (2012) completam essa ideia, mas chamam atenção para uma supervalorização que o conceito teria. Para esses autores,

o conceito de interatividade se origina da nova exigência de operacionalidade imposta ao desempenho de máquinas, a partir do momento em que se concebeu que, em algumas situações específicas, elas pudessem vir a substituir, com vantagens de simplificação e rapidez, o contato humano direto. Mas o termo rapidamente extrapola o universo tecnológico, a exigência de implantação do "dispositivo conversacional" invadindo outros domínios e contagiando todo tipo de "comunicação" indiretamente realizada. So-

Rev.Cad.Comun. Santa Maria, v.22, n.1, art 7, p.149 de 169, jan/abr.2018 
bretudo no âmbito da propaganda e marketing e das ditas "novas mídias", a interatividade, entendida em um sentido bem amplo, parece garantir uma aproximação inédita com o consumidor, de que resultam algumas falácias relativas à iniciativa e à escolha supostamente concedidas ao usuário, tanto quanto consequências comerciais muito diretas (VALLE; BOHADANA, 2012, p. 974).

Assim concluem os autores que não se pode perder de vista a falta de cuidado nos estudos mais recentes que mostram a associação da

a interatividade à ruptura dos antigos paradigmas comunicacionais, pregando-se a transição do modo de comunicação "massivo" para o "interativo". Em resumo, propõe-se a interatividade como palavra de ordem de uma verdadeira revolução social que, amparada pela informática, conduziria a uma ampla reconfiguração das comunicações humanas (VALLE; BOHADANA, 2012, p. 974).

De forma diferente, Matta (2005, p. 434), dando contornos mais positivos e mais promissores quanto à interatividade, e retomando e expandindo uma relação na comunicação em rede sob em viés mais político, explica que haveria

um potencial de transformação social e da prática humana no relacionamento colaborativo e pleno de interatividade, possibilitado às comunidades humanas pelas tecnologias da informação. Mas esse potencial se realiza a partir do diálogo concreto entre as necessidades dos sujeitos e das coletividades e a capacidade das tecnologias de atender a essas necessidades.

Talvez por necessidade de cautela, e como meio termo, Cardoso (2010) vê que as mudanças recentes não devem ser creditadas somente à inovação tecnológica e aos próprios instrumentos de mediação. Para ele, há também a influencia da forma como os utilizadores escolheram apropriar-se socialmente desses instrumentos e, consequentemente, como construíram novos processos de mediação. Reside aí a necessidade de busca de compreensão de como o sistema de media é organizado, mas também de como o configuramos através da mediação.

Por isso, a crescente centralidade dos media, no exercício de poder e na condução do nosso dia a dia, coloca o estudo da mediação no topo da ordem do dia da investigação social, exigindo a compreensão da forma como os processos de comunicação mediada moldam tanto a sociedade como a

Rev.Cad.Comun. Santa Maria, v.22, n.1, art 7, p.150 de 169, jan/abr.2018 
cultura, mas também como a mediação molda o sistema de media (CARDOSO, 2010).

Os bons argumentos do autor fazem com que a cautela seja levada em conta. Mas, como ele nota, surge outra questão fundamental, que retomando um, viés otimista: ultrapassar o modelo de comunicação em massa para e encontramo-nos num modelo baseado na comunicação em rede. "[...] Mais importante do que a mudança tecnológica, para a alteração no sistema de media, tem sido a forma como os utilizadores de media, nos seus processos de mediação privados, públicos ou de trabalho, moldam as suas dietas e matrizes de media" (CARDOSO, 2010).

\section{INTERATIVIDADE E POLÍTICAS DE RELACIONAMENTO NAS REDES SOCIAIS}

Como se pode depreender do que já foi aqui exposto, e dado o cenário atual da sociedade, essas mudanças impactarão na forma como as empresas se relacionam com seus públicos consumidores (BARROS, 2010). Ou, ao menos, em estudos que buscam explicar o fenômeno, como o quer Cardoso (2010), e na apropriação e tentativa posterior de adequar essas conceituações no campo prático das organizações.

Formas positivas sobre a interatividade e relacionamento na internet, como a de Thompson (2008 apud BARROS, 2010), por exemplo, mostram que enquanto estas alterações nas interações e nos relacionamentos são decorrentes da mudança na mediação, as inovações ocorridas nas mídias digitais fizeram com que as organizações percebessem que é possível ir além de uma comunicação linear ou até mesmo circular com seus púbicos. Mais que isso, o ambiente computacional, as novas mídias, internet, etc., tecnologias que efetivamente dão suporte ao relacionamento das empresas nos dias de hoje, mas definem novos desafios às organizações.

Nassar (2006, p. 37) é ainda mais enfática em sua análise, sob um olhar do campo comunicacional e organizacional. Para ela

Os territórios digitais cada dia mais presentes em nosso cotidiano tiraram o poder da empresa como produtora de conteúdo. As características tecnológicas, as interações entre homem e máquina, enfraqueceram a diferenciação analógica entre emissor e receptor. Neste quadro, a empresa é mais um importante produtor de conteúdo no âmbito de uma rede de protagonistas que contrapõem o tempo todas as suas interpretações a respeito de prati-

Rev.Cad.Comun. Santa Maria, v.22, n.1, art 7, p.151 de 169, jan/abr.2018 
camente todos os temas que antes eram propostos e discutidos apenas nas salas das direções organizacionais.

Pensada a organização como um sistema social, e já antecipando parte do que será discutido mais a frente, Nassar (2006, p. 33-34) argumenta que

tudo aquilo que denominamos de imaterial - a cultura, a identidade, a imagem, a marca, a reputação, a missão, visão e valores organizacionais - é definido nas cadeias relacionais. [...] É impossível pensar uma empresa e os seus componentes fora do ambiente onde está inserida, de seus mercados e da sociedade. [...]. A organização perdeu a sua centralidade autoritária. Um alguém organizacional só é "sustentável”, "responsável social”, "politicamente correto", "explorador”, "corrupto”, nas suas relações com os outros. A empresa se estrutura, se configura (desfigura), adquire e consolida (ou desfaz) a sua identidade quando estabelece relações com as suas alteridades. É uma ficção determinar o que uma empresa é, ou quer ser, a partir da sala dos administradores, da cabeça dos comunicadores.

Parece ser nesse sentido que as mídias digitais têm sido tomadas como propiciadora de meios e oportunidades para a constituição de modos diferenciados de relacionamento (BARROS, 2010). Por outro lado,

Se os antigos consumidores eram tidos como passivos, os novos consumidores são ativos. Se os antigos consumidores eram previsíveis e ficavam onde mandavam que ficassem, os novos consumidores são migratórios, demonstrando uma declinante lealdade a redes ou a meios de comunicação. Se os antigos consumidores eram indivíduos isolados, os novos consumidores são conectados socialmente. Se o trabalho de consumidores de mídia já foi silencioso e invisível, os novos consumidores são agora barulhentos e públicos (JENKINS, 2008, p. 45 apud BARROS 2010).

Para Mello (2010), a internet não constitui apenas mais um canal de comunicação ou uma mídia, mas muito mais a introdutora de uma nova lógica no mercado, como nos exemplos da repercussão de uma experiência negativa na forma viral (forma rápida com que algo ou algum assunto é recebido, conhecido e disseminado na internet) e em tempo real, podendo atingir miIhares ou até milhões de consumidores. Ao mesmo tempo, a "multiplicação de mídias e a interatividade das redes sociais, é preciso interagir com os consumidores o tempo todo, e em todos os pontos de contato, o que está 
obrigando o marketing e a comunicação mercadológica a se reinventarem". Para Lazzarato, Negri e Jesus (2001, apud Mello 2010, p. 45) essas formas das metamorfoses do ambiente mercadológico valorizam a comunicação de marketing, já que "a ativação, seja da cooperação produtiva, seja da relação social com o consumidor, é materializada dentro e através do processo comunicativo". Mas também complexificam todos os processos e obrigam à revisão dos velhos paradigmas.

Ainda assim, essa transição da comunicação mercadológica envolve uma migração dos investimentos nas mídias tradicionais de massa para as novas mídias on-line e móveis. $\mathrm{E}$

nesse sentido, ao mesmo tempo em que problematiza a comunicação de marketing, a revolução digital e as novas mídias interativas abrem também um horizonte de oportunidades para as empresas - ou pelo menos para as que souberem se adequar à nova lógica e tirar partido das tecnologias de personalização para se relacionar com seus públicos como nunca antes. Por um lado, os novos meios possibilitam interagir com o consumidor onde ele estiver, no seu canal de preferência e no momento mais adequado para esse contato. Por outro, se antes eram necessários investimentos vultosos em pesquisas para ouvir os consumidores, investigar seus comportamentos e preferências - com as distorções inerentes às pesquisas de opinião -, agora é possível dialogar diretamente com eles para captar esse conhecimento e transformá-lo em produtos e serviços que lhes interessem (MELLO, 2010).

Mesmo que se possa imputar otimismo ao argumento, o que mantém o sistema de relacionamento nesse cenário é o fluxo permanente de informações entre seus participantes. Ao mesmo tempo, esse sistema já vem representando ganhos para as muitas organizações. Também de forma otimista, Barros (2010), ao explicar esse fenômeno, trás importantes achados para sua compreensão. Para ele

os dados se movimentam pela rede de modo que os envolvidos saibam progressivamente mais sobre o outro até o ponto em que se estabeleça a credibilidade no que é dito e na própria relação entre eles. Portanto, o relacionamento se dá quando as partes envolvidas incorporam conceitos como confiança, credibilidade, atendimento de necessidades, personalização, fidelização e troca de interesses. A interação e a troca de informações permitem que as empresas conheçam quem são seus públicos e faça uso deste conteúdo para elaborar produtos, serviços e comunicações com

Rev.Cad.Comun. Santa Maria, v.22, n.1, art 7, p.153 de 169, jan/abr.2018 
maior adequação às necessidades e ao perfil do consumidor. Forma-se então uma espécie de círculo vicioso em que as empresas têm acesso à enorme audiência da rede e aos seus conteúdos, os usuários usufruem dos benefícios oferecidos pelas organizações em suas redes de relacionamento e consequentemente as empresas conquistam mais adeptos porque tornam as suas propostas mais atraentes aos olhos dos consumidores.

Sob esse argumento, portanto, o que caracterizaria o relacionamento estabelecido por empresas e seus públicos na cibercultura são as relações interdependentes e processos de negociação. Neles cada interagente participa da construção e é afetado mutuamente, de forma dialógica.

\section{ADEQUAÇÕES NA COMUNICAÇÃO ORGANIZACIONAL}

O círculo crítico e teórico de estudos sobre o ambiente organizacional, a partir daí, irá obviamente ser afetado pelas conceituações trazidas pela influência da internet e das tecnologias da informação, e pelo pensamento dialógico. Para Nassar, sob esse olhar, a comunicação vista apenas como ferramenta, como técnica, tem pouca utilidade, e a comunicação organizacional, enquanto pensamento e ação, não passa de uma tentativa legitimar ou negociar uma determina interpretação. Por isso a comunicação deve ser

meta-organizacional, ela acontece, é desenhada em um ambiente relacional, enredado, em que a empresa ou instituição não é mais o centro, mas é co-participante. A organização não tem mais o poder de dizer que quer ser percebida de uma forma ou de outra, a partir de uma área de comunicação ou de gestão. Ela será aquilo que a rede relacional perceber; será aquilo que expressará uma intensa negociação e trocas. Essa rede não admite participantes passivos (NASSAR, 2006, p. 34).

Baldissera (2010), ao pensar a comunicação organizacional e ao considerar a necessidade das organizações em convocarem sujeitos para uma relação, nota que as empresas, em termos relacionais, projeta discursos planejados e carregados de intenções de negócios que trazem marcas do contexto em que a interação se dá, dos interlocutores e da própria relação, de modo que a análise do discurso organizacional não pode prescindir da análise do contexto e da própria interação, como preconizado pelo paradigma relacional.

Assim, têm na comunicação organizacional modos de ver um objeto pri-

Rev.Cad.Comun. Santa Maria, v.22, n.1, art 7, p.154 de 169, jan/abr.2018 
vilegiado e de onde se pode analisar o fenômeno da comunicação, o contexto social em que se insere, os sujeitos da relação e a produção de sentido (BALDISSERA, 2010). Ou seja, hoje as organizações se reconstituem e reconfiguram nas suas relações, nos usos da linguagem, práticas discursivas e produção de sentido também através da lógica midiática pautada pelas tecnologias da informação.

Na esfera dessas novas lógicas, a informação e comunicação tende a ganhar ainda mais importância tendo como meios instrumentos e processos poderosos de realização das potencialidades estratégicas e para a ampliação e integração das estruturas organizacionais. Isso significa que as organizações precisam repensar, complementar e aprimorar seus referenciais teóricos e metodológicos tradicionais, formulando e disseminando estratégias que levem em conta os processos comunicacionais como suportes eficazes e competentes para o agir e existir delas (CARDOSO, 2006).

Mas para isso, como observou KUNSCH (2007, p. 39-40), constitui-se condição sine qua non situar-se na sociedade onde estamos inseridos para análises de cenários e contextos, cujas leituras são objeto de interpretações para se estabelecer diagnósticos situacionais. Eles, por sua vez,

constituem subsídios indispensáveis no processo do planejamento e da gestão estratégica da comunicação corporativa. Neste sentido, não adianta as organizações utilizarem simplesmente as poderosas armas das novas tecnologias da informação e da comunicação, por modismos, sem antes terem consciência das bases que irão justificar a escolha de determinadas mídias digitais.

A comunicação organizacional reposiciona-se como aquilo que abrange todas as formas de comunicação utilizadas pela organização para relacionar-se e interagir com seus públicos, interno e externo (SCROFERNEKER, 2000; SCROFERNEKER, 2006). Ou, ainda, como notou Deetz (2001, apud LAUS 2016, p. 35), de forma ampla, ela é uma forma de descrever e explicar a organização, não apenas como um fenômeno que ocorre na organização. Isto é, a comunicação é a organização, o que definiria uma opção próxima da compreensão sistêmico-discursiva.

No Brasil, o campo da comunicação se realiza no espaço das organizações produtivas desde a emergência e posterior consolidação do processo industrial nacional, sendo que 
a dimensão instrumental da comunicação e seu caráter mecanicista teve sua contemporaneidade associada a esse desenvolvimento. As mutações e transformações que se deram no âmbito do desenvolvimento socioeconômico ao longo de décadas recentes e o processo de globalização da atualidade fazem sugerir que o processo comunicacional nas organizações também passou por mutações (NASSAR, 2006, p. 33).

Essas mutações e redefinições, mais atuais, remontam os primeiros estudos de comunicação organizacional, de perfil científico, nos anos 1940, em que a comunicação passou a interessar aos pesquisadores, ainda que se reconheçam em alguns textos clássicos das áreas de economia e administração anteriores faziam referências a aspectos típicos do campo da comunicação organizacional (CURVELLO, 2002).

Mais recentemente, com os estudos sistêmicos, a investigação precipita-se da metáfora da organização como "contentora" de comunicação para a sua visão como que fundamental ao estudo das organizações: as organizações deveriam ser vistas como sistemas onde interagem indivíduos, que pela comunicação estão ativamente envolvidos no processo de criar e recriar a sua ordem social única. A comunicação organizacional é, portanto, um processo de criação de estruturas de significado coletivas e coordenadas, por meio de práticas simbólicas direcionadas a consecução de objetivos organizacionais (RUÃO, 2016). O que só reforça a importância de se pensar a comunicação organizacional a partir de abordagens sistêmicas, complexas e discursivas (BALDISSERA, 2011; DEETZ, 2001; SCROFERNEKER, 2006), sobretudo se pensados o instante comunicacional.

Laus (2016, p. 35) se refere a esse tipo de comunicação como

um processo social de circulação, multiplicação e disputa de sentidos, configurado nos desvios entre produção e reconhecimento, formando uma rede complexa de sentidos, em que uma comunicação é condição para existência da outra. Essa rede de sentidos, continuamente (re)produzida no âmbito dos sistemas organizacionais e nas suas relações com o ambiente (formado por outros sistemas e por indivíduos), é engendrada em desvios, dissensos e indeterminações .

Como salientado por Baldissera (2011, p. 118), sem isso, corre-se um risCO:

Rev.Cad.Comun. Santa Maria, v.22, n.1, art 7, p.156 de 169, jan/abr.2018 
diante das características da sociedade contemporânea, tais como a urgência nas decisões (e, portanto, o pouco tempo para investigar e refletir), o desejo de poder (exercer-se sobre a alteridade), o enfraquecimento dos vínculos, a velocidade com que as informações circulam (potência tecnológica), a tendência ao espetáculo, a valorização do imediato e o desejo de fórmulas que permitam a mensuração de tudo - inclusive do intangível -, a ideia de Comunicação Organizacional parece ser reduzida, particularmente no nível das práticas cotidianas, à comunicação planejada. A postura tende a ser a da supervalorização dos processos planejados em detrimento de todas as demais realizações comunicacionais. Especial atenção recebem os processos que, de alguma forma, se traduzem em algo tangível, como os jornais institucionais, as campanhas publicitárias, os eventos, os sites, os materiais informativos para imprensa (e a clipagem) e outros. Ações mensuráveis (tradução em números) são mais valorizadas.

Baldissera (2011, p. 118) tem em mente as ideias de Morin (2000; 2002), segundo o qual

\begin{abstract}
a Comunicação Organizacional não se restringe ao âmbito do organizado, à fala autorizada, aos processos formais, à comunicação da e/ou na organização. Exige olhar para além das manifestações organizadas, aparentemente coerentes, de modo a atentar para, entre outras coisas: a dinamicidade organizacional; os processos que mantêm a organização distante do equilíbrio; o estado de incerteza e de permanente desorganização/(re)organização (tensões, disputas, perturbações); a necessária interdependência ecossistêmica (outros sistemas e subsistemas); e os processos recursivos.
\end{abstract}

A partir do olhar da complexidade da comunicação no âmbito das relações organizacionais, Baldissera $(2008$; 2010; 2011) problematizara a discussão por meio de três dimensões passíveis de análise comunicacional: organização comunicada, organização comunicante e organização falada.

Para ele, a organização comunicada caracteriza-se, fundamentalmente, pela fala oficial da organização, ou seja, o que ela diz sobre si mesma, e identifica como potencialidade para trazer algum tipo de retorno (satisfação pessoal, prestígio imagem-conceito, poder simbólico, clientes) e, portanto, entende que mereça ser tornado público (BALDISSERA, 2010).

Já num grau mais complexo, 
pode-se falar da Comunicação Organizacional em seu nível de organização comunicante. Aqui, ultrapassando o âmbito da fala autorizada, atenta-se para todo processo comunicacional que se atualiza quando, de alguma forma e em algum nível, qualquer sujeito (pessoa, público) estabelecer relação com a organização. Além dos processos planejados, também assumem relevo os processos que se realizam na informalidade; inclusive aqueles que irrompem sem que a organização tenha conhecimento. Assim, mesmo que a organização não deseje comunicar, se alguém - alteridade - atribuir sentido a algo e/ou alguma coisa dela e assumir isso como comunicação, então será comunicação (BALDISSERA, 2011).

Para esse autor, essa compreensão permite dar relevo aos processos dialógico-recursivos, pois atenta para a possibilidade e fertilidade de ocorrência de relações comunicacionais que escapam ao planejamento e controle (BALDISSERA, 2011).

No âmbito da organização falada têm-se os processos de comunicação informal indiretos, que se realizam fora do âmbito organizacional, mas que dizem respeito à organização. Esses processos contemplam outras materializações comunicacionais que remetem às organizações, mas que pouco são pensadas com comunicação organizacional, tais como nos processos que se atualizam entre colegas de trabalho quando, juntos, participam de um jogo de futebol e discorrem sobre a organização. Ou ainda nas manifestações sobre ela nas relações familiares, nos processos especulativos e nas conversas sobre a organização em momentos informais (BALDISSERA, 2008; BALDISSERA, 2010).

As organizações de saúde comportam, nesse sentido, uma complexidade e uma contrapartida no fluxo comunicacional estabelecido na internet, como acontece com as operadoras de saúde. Ambiente comunicacional e questões intrínsecas ao mercado de planos de saúde, se voltado agora o olhar para as empresas que compõe o setor, suscitam adequações. De todo modo, o instante comunicacional e tecnológico, ao menos, faz com sejam necessários mais debate em relação á comunicação em saúde.

\section{COMPLEXIDADE DA COMUNICAÇÃO EM SAÚDE}

Ao longo dos anos, diversos modelos comunicativos têm sido vivenciados nas práticas em saúde, vinculados a ações de imposição, informação e educação, de acordo com os modelos assistenciais em saúde hegemônicos (CORIOLANO-MARINUS et al., 2014). Na prática, boa parte das campanhas

Rev.Cad.Comun. Santa Maria, v.22, n.1, art 7, p.158 de 169, jan/abr.2018 
de saúde tiveram como base o modelo informacional e monológico de comunicação. Como é possível apreender, ao se levar em conta as críticas sobre esse modelo, quando

\begin{abstract}
aplicado ao campo da comunicação em saúde, esse modelo fragmentado do processo comunicativo, confere-se o poder da palavra ao pólo emissor, considerado o detentor de conhecimentos e informações a serem transmitidas ao pólo receptor, com vistas à mudança de comportamentos em vista a melhoria da saúde (KELLY-SANTOS; MONTEIRO; ROZEMBERG, 2009).
\end{abstract}

Assim, esse modelo, que se caracteriza por princípios verticalizados de intervenção e que acredita no "envio" da informação "correta" e "científica", é questionado se seria suficiente para a transformação das normas de comportamento. No modelo informacional aplicado à saúde, segundo Martínez-Hernáez (2010, apud CORIOLANO-MARINUS et al., 2014, p. 1365),

acredita-se, ainda, que o coletivo dos usuários é "vazio" de conhecimentos, cabendo à educação em saúde preencher esse vazio [...], no qual os diversos fenômenos de vida, saúde e doença, de natureza multidimensional, são reduzidos aos aspectos meramente biológicos e resultam em práticas que desconsideram a historicidade, a cultura e a complexidade do ser humano.

Outros estudos mostram essa realidade no Brasil em campanhas em saúde, como a maioria empreendida pelo Ministério da Saúde, em que é privilegiado o saber médico para fomentar hábitos e práticas de promoção da saúde e a adesão da população aos procedimentos médico-sanitários (ARAÚJO; CARDOSO, 2007; ROZEMBERG; SILVA; VASCONCELLOS-SILVA, 2002).

Com base nesses equívocos, as

instituições de saúde podem engendrar comunicações confusas, ambíguas, contraditórias e até errôneas, dificultando o alcance dos próprios objetivos organizacionais. A complexidade e o sequenciamento extenso de muitas intervenções de saúde - cujos resultados podem ser pouco evidentes em curto prazo - somados à diversidade de agentes sociais envolvidos constituem fatores perturbadores de uma efetiva comunicação em prol da adesão ao tratamento por parte do paciente, da prevenção de doenças e promoção da saúde do usuário e do desenvolvimento da autonomia e participação ativa do cidadão (ARAUJO, 2009). 
Com o objetivo de definir o campo de estudo, bem como, as competências em relação à saúde, estudiosos e instituições das áreas de informação, educação, comunicação e saúde, têm dialogado seus saberes na definição de conceitos sobre a comunicação em saúde. Não se trata somente de informações sobre saúde nas mídias, mas de definição de modelos e processos de comunicação não midiáticos que não abarquem uma compreensão monomodal do processo comunicativo.

Por isso Lefevre, Lefevre e Figueiredo (2010, p. 9) propõe uma acepção mais ampla, que comporte a dimensão dialógica da linguagem. Para eles,

a comunicação em saúde pode ser vista como uma relação de troca de ideias ou mensagens que, quando bem sucedida, promove um contato entre o pensamento sanitário e o pensamento do senso comum, afetando ambos e fazendo avançar a consciência coletiva sobre as questões de saúde e doença em uma dada formação sociocultural. Para que isso ocorra, é preciso considerar as representações sociais sobre saúde e doença existentes nas formações socioculturais, ou seja, o sistema de ideias que constitui o modo de pensar saúde e doença próprio do grupo ao qual o(s) indivíduo(s) pertence $(\mathrm{m})$.

Nesse ponto de vista, em seu contexto dialógico, a comunicação em saúde passa a ser um espaço sociodiscursivo de natureza simbólica, permanentemente atualizada por contextos específicos, formados por teorias, modelos e metodologias, bem como por agentes, instituições, políticas, discursos, práticas, instâncias de formação, lutas e negociações (ARAÚJO; CARDOSO, 2007).

Buss (1999) também reconhece que a comunicação em saúde precisa ser entendida mais além de seu significado midiático latu sensu, como um fenômeno produtor de sentido social. Na linha de Lefreve etl al. (2010), ele a considera um agente de mobilização social que, além de democratizar a informação, permite que a população defina sua própria conduta, individual ou coletivamente, adotando ou fortalecendo escolhas de bem-estar baseadas em valores culturais. Além disso, pare ele, uma vez que a participação ativa e permanente da população é central no conceito e na prática da promoção da saúde, "torna-se imprescindível a provisão de informações para o exercício da cidadania, assim como iniciativas do poder público nos campos da educação e da comunicação em saúde”.

Por fim, atente-se para o fato de que,

Rev.Cad.Comun. Santa Maria, v.22, n.1, art 7, p.160 de 169, jan/abr.2018 
como em todas as políticas de saúde, também as políticas de comunicação em saúde necessitam, para serem implementadas, de planos estratégicos, com a identificação precisa dos problemas a serem enfrentados, das características do público a ser contatado, dos meios de comunicação mais adequados a serem mobilizados, assim como da implementação dos programas definidos e de seu acompanhamento e avaliação. No entanto, não se pode compreender ou transformar a situação de saúde de um indivíduo ou de uma coletividade sem levar em conta que ela é produzida nas relações com o meio físico, social e cultural (KRUSCHEWSKY et al., 2016, p. 172).

Além disso, nessa múltipla relação entre a comunicação e a saúde, a informação sobre boas práticas para a saúde individual pode ajudar na escoIha de comportamentos em diversas esferas, na prevenção de doenças e, em geral, no desenvolvimento de uma cultura da saúde.

Igualmente, a democratização das informações sobre a situação de saúde e do sistema de saúde, divulgadas de diversas formas, entre as quais através de meios de comunicação de massas, pode contribuir para um melhor entendimento dos determinantes da saúde e para a construção de um discurso político e reivindicatório consistente e persuasivo que mobilize e reforce a ação da comunidade na afirmação de seus direitos e no seu enfrentamento com o Estado (BUSS, 1999, p. 126)

Traçado esse objetivo, isso claramente demandará esforços de diversas esferas. No que tocam os meios de comunicação, segundo Bydlowski, Westphal e Pereira (2004), o envolvimento é quase nulo. Para esses estudiosos, as mídias, em algumas situações, até mesmo colocam-se contra certos pressupostos de promoção da saúde, reforçando uma visão curativa e biomédica do processo saúde-doença. Por isso existe necessidade de mudança de pressupostos e da cooperação destes meios no sentido de valorizar e de facilitar condições de vida e de saúde.

Coriolano-Marinus et al. (2014) entendem que, para tais fins, a compreensão trazida pela comunicação dialógica deve estar presente e diversas esferas da saúde, além de presente na instrumentalização dos trabalhadores de saúde, desde a graduação, com saberes que proporcionem o exercício de práticas comunicativas diferenciadas. E concluem que, apesar das críticas, ainda persistem desafios para propiciar experiências formativas dialógicas nos processos de educação permanente e nos cenários de assistência à saú-

Rev.Cad.Comun. Santa Maria, v.22, n.1, art 7, p.161 de 169, jan/abr.2018 
de. Para eles, sem esses meios, não se pode produzir o compartilhamento de saberes que conduzam à compreensão e entendimento entre os vários interlocutores envolvidos no ato comunicativo.

Indo além, é preciso também verificar se há e deve haver esse entendimento e compreensão pelos diversos agentes em saúde, dentre eles as operadoras de saúde, que, no sentido apontado, demonstra ser um importante interlocutor na comunicação em saúde. Ao mesmo tempo, poder-se-ia perguntar pelos meios e espaços disponíveis em que ações nesse sentido fossem possíveis.

\section{O FACEBOOK COM LOCUS DE INTERAÇÃO, RELACIONAMENTO E PROMOÇÃO DA SAÚDE}

Um artigo recente buscou discutir como o Facebook tem sido usado pelas operadoras de saúde brasileiras, dando a ele importante papel de se espaço para estratégias de promoção da saúde, de tal modo que os sites de rede social gerariam grandes oportunidades a serem exploradas pelas operadoras para alavancar o relacionamento e a interação com os sujeitos (MARCELINO; SOUSA; BRUCK, 2016).

A discussão teve por base estudos que vêm demonstrando o alcance do Facebook e de outros sites de rede social no compartilhamento de informações, na construção de comunidades e em prol da ação em saúde (RAMANADHAN et al., 2013; SYRED et al., 2014). Mais que isso, que as organizações tendem a usar os SRS's para construir relacionamentos, mas estando muitas vezes usando-os por um viés predominantemente tecnicista, gerencial e prescritivo. Tais estudos ressaltam a necessidade de adoção de uma nova perspectiva que permita a conexão e a relação entre os interlocutores (LIMA, 2008; OLIVEIRA; PAULA, 2005; RIBEIRO; MENDONÇA; MENDONÇA, 2007).

Uma das peculiaridades desses sítios na internet é que permitem aos usuários encontrar as informações que lhes interessam e expressar em rede suas opiniões, pensamentos e versões dos fatos sem submissão a filtros (editores, jornalistas, empresas de comunicação, etc.) (MARCELINO et al., 2016). Ou, como já apontava Lévy (1999), essas novas tecnologias estimulam uma comunicação comunitária, transversal e recíproca. Na contramão do paradigma informacional, desconsidera que a comunicação possa ser administrada, gerenciada. Ainda que mereça ressalvas, fica patente que, sem

Rev.Cad.Comun. Santa Maria, v.22, n.1, art 7, p.162 de 169, jan/abr.2018 
isso, opor-se-ia à lógica relacional da rede, além de dificultar a comunicação entre as pessoas e as instituições com as quais se relacionam.

Nesse ambiente, o impacto das gerações tecnológicas, no âmbito organizacional, vem transformando o contexto social e reconfigurando o estoque cognitivo dos sujeitos, seus discursos e suas interações (LIMA, 2008). Portanto, as possibilidades criadas passam por um dimensionamento, tanto por seu aspecto organizacional quanto em relação à saúde, já que

torna-se necessário pensar a gestão da comunicação em que individuo esteja em evidência, valorizando o seu potencial criador e considerando a subjetividade e a afetividade em uma perspectiva dialógica, sob uma comunicação mais estratégica. Note-se que o que está em evidência é todo e qualquer individuo da organização. Além disso, o que retorna ao tema em discussão, em que se tem em vista a promoção da saúde, a comunicação estratégica ganha corpo e a questão da interatividade é retomada (MARCELINO et al., 2016).

Ribeiro e Marchiori, (2008, apud MARCELINO; SOUSA; BRUCK, 2016, p. 415), de forma proposicional, observou que o diálogo é uma técnica que permite o pensamento conjunto e compartilhado promovendo, através da "união das falas", o processo de interatividade. Esse processo que vem a ser o elemento fundamental do paradigma relacional, donde a dinâmica é voltada para as ligações, para a formação de redes. Daí a expressão "redes de conversação" - experiências de reflexão conjunta, geração de ideias, educação mútua e produção compartilhada de significados.

Assim, fica evidente a importância da interação e da interatividade para que se estabeleça uma dimensão criadora entre as diferentes vozes, para a interpretação dos sentidos e para a construção coletiva de pensamento, ao mesmo tempo em que se refirma esse força nos meios digitais (RIBEIRO et al., 2007). E esse panorama comunicacional justifica, em parte teoricamente, a importância estratégica que as redes sociais adquirem. Sob um ponto de vista dinâmico, redimensionam as estratégias de comunicação em saúde, já que as organizações tornam-se sujeitos complexos e, no relacionamento com os seus membros e com a sociedade, reconfiguram determinado contexto de interações com seu público (CARDOSO, 2010; LIMA; ABBUD, 2015).

Se por um lado as mídias sociais podem facilitar a comunicação entre os clientes e entre os clientes e a organização (MARCELINO et al., 2016), por outro o valor dos sites de rede social é a sua capacidade de criar, bidireccio-

Rev.Cad.Comun. Santa Maria, v.22, n.1, art 7, p.163 de 169, jan/abr.2018 
nalmente, a comunicação interativa, contribuindo para o alcance dos objetivos por parte das organizações, se admitida certa renúncia do controle sobre o conteúdo e de uma abordagem mais participativa (RAMANADHAN et al., 2013; THACKERAY et al., 2013).

Atualmente, pode-se dizer que as OPS continuam a investir nas mídias de massa, mas passaram a explorar os sites de redes sociais digitais devido a essas potencialidades, como se vê na criação de perfis de todas elas no Facebook. Como se viu, uma organização que inclui esse tipo de mídia como parte de sua estratégia de comunicação tem o potencial de aumentar o nível de diálogo com seus clientes. De tal modo, a busca da universalização dos progressos tecnológicos traz, quando pensando a questão da saúde, uma oportunidade a ser explorada pelas Operadoras de Planos de Saúde na promoção da saúde. Mas para tanto, faz-se necessário que elas estejam atentas à necessidade de adoção de um modelo comunicacional mais efetivo e que esse seja sinérgico à interatividade latente nas mídias sociais, caracterizado pelo paradigma da interatividade e construção conjunta de conhecimentos (MARCELINO et al., 2016). 


\section{REFERÊNCIAS}

ALBUQUERQUE, S. L. A.; RODELLA, C. A. A comunicação institucional e o conteúdo gerado pelos usuários no Facebook envolvendo a companhia TIM. Revista de Estudos da Comunicação, v. 13, n. 32, 2012.

ARAÚJO, I. S.; CARDOSO, J. M. Comunicação e saúde. Rio de Janeiro: FIOCRUZ, 2007.

ARAUJO, T. C. C. F. D. Comunicação em saúde: contribuições do enfoque observacional para pesquisa e atuação. Arquivos Brasileiros de Psicologia, v. 61, n. 2, 2009.

BALDISSERA, R. Por uma compreensão da comunicação organizacional. In: SCROFERNEKER, C. M. A. (Ed.). O diálogo possível: comunicação organizacional e paradigma da complexidade. Porto Alegre: EDIPUCRS, 2008.

BALDISSERA, R. A complexidade dos processos comunicacionais e interação nas organizações. In: MARCHIORI, M. O. (Ed.). Faces da cultura e da comunicação organizacional. . São Caetano do Sul: Difusão, 2010.

BALDISSERA, R. Comunicação Organizacional na perspectiva da complexidade. Revista Organicom, v. 6, n. 10/11, 2011.

BARROS, A. C. P. D. Relacionamento Mercadológico nas Mídias Interativas Digitais: Inovações na comunicação transmidiática entre empresas e consumidores. Revista de pós graduação em comunicação da PPGC-UFPB, n. 3, 2010.

BUSS, P. M. Promoção e educação em saúde no âmbito da Escola de Governo em Saúde da Escola Nacional de Saúde Pública. Cadernos de Saúde Pública, v. 15, p. S177-S185, 1999.

BYDLOWSKI, C. R.; WESTPHAL, M. F.; PEREIRA, I. M. T. B. Promoção da Saúde. Porque sim e porque ainda não! Saúde e sociedade, v. 13, n. 1, p. 14-24, 2004.

CARDOSO, G. Da comunicação em massa à comunicação em rede: modelos comunicacionais e a sociedade de informação. In: CARDOSO, G. (Ed.). Mutações do visível: da comunicação em massa à comunicação em rede. . Rio de Janeiro: Pão e Rosas, 2010. p.23-52.

CARDOSO, O. D. O. Comunicação empresarial versus comunicação organizacional: novos desafios teóricos. RAP Rio de Janeiro, v. 40, n. 6, p. 1123-44, 2006.

CORIOLANO-MARINUS, M. W. D. L. et al. Comunicação nas práticas em saúde: revisão integrativa da literatura. Saúde e Sociedade, v. 23, n. 4, p. 1356-1369, 2014. 
CADERNOS DE COMUNICAÇÃO

UNIVERSIDADE FEDERAL DE SANTA MARIA

CURVELLO, J. J. A. Estudos de comunicação organizacional: entre a análise e a prescrição. XXV CONGRESSO BRASILEIRO DE CIÊNCIAS DA COMUNICAÇÃO-Intercom-NP Relações Públicas e Comunicação Organizacional. Anais em CD. Salvador/BA, setembro, 2002.

DEETZ, S. Conceptual foundations. In: JABLIN, F. M. e PUTNAM, L. L. (Ed.). The new handbook of organizational communication: Advances in theory, research, and methods. Thousand Oaks: Sage, 2001. p.3-46.

FRANÇA, V. et al. Estratégias e culturas da comunicação. Brasília: Universidade de Brasília, 2002.

FRANÇA, V. V. Paradigmas da comunicação: conhecer o quê? Ciberlegenda, n. 5, 2001.

GOLD, J. et al. A systematic examination of the use of online social networking sites for sexual health promotion. BMC public health, v. 11, n. 1, p. 1, 2011.

GOLD, J. et al. Developing health promotion interventions on social networking sites: recommendations from The FaceSpace Project. Journal of medical Internet research, v. 14, n. 1, p. e30, 2012.

JENKINS, H. Cultura da convergência. São Paulo: Aleph, 2008.

KELLY-SANTOS, A.; MONTEIRO, S.; ROZEMBERG, B. Significados e usos de materiais educativos sobre hanseníase segundo profissionais. Cad. saúde pública, v. 25, n. 4, p. 857-867, 2009.

KRUSCHEWSKY, J. E.; KRUSCHEWSKY, M. E.; CARDOSO, J. P. Experiências pedagógicas de educação popular em saúde: a pedagogia tradicional versus a problematizadora. Rev. Saúde.Com, v. 4, n. 2, 2016.

KUNSCH, M. M. K. Comunicación organizacional en la era digital: contexos, recursos y posiblidades. Signo y Pensamiento, n. 51, p. 38-51, 2007.

LAUS, V. M. Elementos comunicacionais da estratégia das organizações. Revista Organicom, v. 12, n. 23, 2016.

LAZZARATO, M.; NEGRI, A.; JESUS, M. Trabalho imaterial: formas de vida e produção de subjetividade. Rio de Janeiro: DP \& A, 2001.

LEFEVRE, F.; LEFEVRE, A. M. C.; FIGUEIREDO, R. Comunicação em saúde e discurso do sujeito coletivo: semelhanças nas diferenças e diferenças nas diferenças. Boletim do Instituto de Saúde, v. 12, n. 1, 2010. 
LENCASTRE, J. A.; MONTEIRO, A. Comunicação e Colaboração On-line no Ensino Superior através da plataforma Moodle. Actas do Challenges, 2009.

LIMA, F. Possíveis contribuições do paradigma relacional para o estudo da comunicação no contexto organizacional. Interfaces e tendências da comunicação no contexto das organizações. São Caetano do Sul: Difusão Editora, p. 109-127, 2008.

LIMA, M. D. C.; ABBUD, M. E. D. O. P. Comunicação Organizacional: Histórico, Conceitos e Dimensões. XIV Congresso de Ciências da Comunicação na Região Norte 2015. Manaus - AM, Brasil.

LUCENA FERREIRA, S.; BIANCHETTI, L. As tecnologias da informação e da comunicação e as possibilidades de interatividade para a educação. Educação e Contemporaneidade, p. $253,2004$.

MARCELINO, P. L.; SOUSA, J. P.; BRUCK, M. S. O uso do facebook pelas operadoras de saúde brasileiras para estratégias de promoção da saúde: uma reflexão filosófica acerca da relação homem e mídia. Sapere Aude-Revista de Filosofia, v. 7, n. 12, p. 404-420, 2016.

MARTÍNEZ-HERNÁEZ, A. Dialógica, etnografia e educação em saúde. Revista de Saúde Pública, v. 44, n. 3, p. 399-405, 2010.

MATTA, A. E. R. Tecnologias para a colaboração. Cadernos Cemarx, v. 1, n. 2, 2005.

MELLO, S. F. M. Comunicação e organizações na sociedade em rede: novas tensões, mediações e paradigmas. 2010. Universidade de São Paulo

MORIN, E. Meus demônios. Rio de Janeiro: Bertrand Brasil, 2000.

MORIN, E. O método 4. Porto Alegre: Sulina, 2002.

NASSAR, M. R. F. O papel da comunicação nas organizações de saúde: oportunidades e desafios. Intercom-XXIX Congresso brasileiro de ciências da comunicação. São Paulo, 2006.

NASSAR, P. A comunicação organizacional na contemporaneidade. Novos Olhares, p. 33-39, 2006.

NICOLAU, M. Fluxo, conexão, relacionamento: um modelo comunicacional para as mídias interativas. Culturas Midiáticas, v. 1, n. 1, 2011. 
CADERNOS DE COMUNICAÇÃO

UNIVERSIDADE FEDERAL DE SANTA MARIA

OLIVEIRA, I. D. L.; PAULA, C. F. C. D. Comunicação organizacional e relações públicas: caminhos que se cruzam, entrecruzam ou sobrepõem? , INTERCOM-Sociedade Brasileira de Estudos Interdisciplinares da Comunicação. XXVIII Congresso Brasileiro de Ciências da Comunicação, 2005. Rio de Janeiro, Brasil.

PARK, H.; RODGERS, S.; STEMMLE, J. Health organizations' use of Facebook for health advertising and promotion. Journal of interactive advertising, v. 12, n. 1, p. 62-77, 2011.

RAMANADHAN, S. et al. Social media use by community-based organizations conducting health promotion: a content analysis. BMC Public Health, v. 13, n. 1, p. 1129, 2013.

RIBEIRO, E. N.; MENDONÇA, G. A. D. A.; MENDONÇA, A. F. A importância dos Ambientes Virtuais de Aprendizagem na busca de novos domínios na EAD. Anais do $13^{\circ}$ Congresso Internacional de Educação a Distância. Curitiba, Brasil. Disponível em: < http://goo. gl/ dbrFol>. Acesso em: 16 set. 2016.

ROZEMBERG, B.; SILVA, A. P. P. D.; VASCONCELLOS-SILVA, P. R. Impressos hospitalares e a dinâmica de construção de seus sentidos: o ponto de vista dos profissionais de saúde. Cad. Saude Publica, v. 18, n. 6, p. 1685-1694, 2002.

RUÃO, T. A organização comunicativa: teoria e prática em Comunicação Organizacional. Braga: CECS - Centro de Estudos de Comunicação e Sociedade, 2016. ISBN 989860056X.

SCROFERNEKER, C. M. A. Perspectivas teóricas da comunicação organizacional. GT Comunicação Organizacional da Intercom, 2000.

SCROFERNEKER, C. M. A. Trajetórias teórico-conceituais da Comunicação Organizacional. Revista FAMECOS: mídia, cultura e tecnologia, v. 1, n. 31, 2006.

SOUZA, L. M. F. O paradigma dialógico no pensamento ocidental sobre tradução: orquestrando vozes. Scientia Traductionis, n. 7, p. 76-92, 2010.

SYRED, J. et al. Would you tell everyone this? Facebook conversations as health promotion interventions. Journal of Medical Internet Research, v. 16, n. 4, p. e108, 2014.

THACKERAY, R. et al. Analysis of the purpose of state health departments' tweets: information sharing, engagement, and action. Journal of medical Internet research, v. 15, n. 11, p. e255, 2013.

THOMPSON, J. A mídia e a modernidade: uma teoria social da mídia. Petrópolis: Vozes, 2008.

VALLE, L. D.; BOHADANA, E. D. A. B. Interação e interatividade: por uma reantropolização da EaD online. Educação \& Sociedade, v. 33, n. 121, p. 973-984, 2012.

Rev.Cad.Comun. Santa Maria, v.22, n.1, art 7, p.168 de 169, jan/abr.2018 


\section{Paola Lanzalotta Marcelino}

Mestre em Gestão Empresarial pela Universidade de Trás-os-Montes e Alto Douro e doutoranda em Ciências da Informação pela Universidade Fernando Pessoa.

\section{Jorge Pedro Sousa}

Professor catedrático e investigador da Universidade Fernando Pessoa e do Centro de Investigação Media \& Jornalismo.

\section{Mozahir Salomão Bruck}

Professor do Programa de Pós-Graduação em Comunicação Social da Pontifícia Universidade Católica de Minas Gerais.

RECEBIDO EM: 31/08/2017

ACEITO EM: 24/10/2017 